\title{
Puerarin as potential treatment in diabetic retinopathy
}

\author{
Mohammad Fathalipour $^{1}$, Amir Mahmoodzadeh ${ }^{2}{ }^{\circledR}$ Omid Safa $^{3}{ }^{\circledR}$, Hossein Mirkhani $^{4,5 *}{ }^{*}$ \\ ${ }^{1}$ Department of Pharmacology and Toxicology, Faculty of Pharmacy, Hormozgan University of Medical Sciences, Bandar Abbas, Iran \\ ${ }^{2}$ Department of Biochemistry, Faculty of Medicine, Shiraz University of Medical Sciences, Shiraz, Iran \\ ${ }^{3}$ Department of Clinical Pharmacy, Faculty of Pharmacy, Hormozgan University of Medical Sciences, Bandar Abbas, Iran \\ ${ }^{4}$ Department of Pharmacology, Faculty of Medicine, Shiraz University of Medical Sciences, Shiraz, Iran \\ ${ }^{5}$ Medicinal and Natural Products Chemistry Research Center, Shiraz University of Medical Sciences, Shiraz, Iran
}

\section{AR T I C L E I N F O}

Article Type:

Review

Article History:

Received: 20 July 2019

Accepted: 13 September 2019

Keywords:

Diabetic retinopathy

Puerarin

Antioxidant

Anti-inflammatory agent

Antiapoptotic agent

\begin{abstract}
A B S T R A C T
Diabetic retinopathy (DR) is one of the most prevalent microvascular complications of diabetes, and the most leading cause of visual loss around the world. The lack of effective and approved treatment in DR is a major challenge for diabetic patients. Nowadays, natural compounds have got attention of the researchers for management of DR. Many evidences suggest that puerarin as a natural polyphenol exerts advantageous effects against DR. In the present review, we summarized the protective effects of puerarin against DR, and discussed the underlying mechanisms of these effects. Puerarin attenuates retinal neovascularization and neurodegeneration in diabetes mellitus, and the underlying mechanisms are related to antioxidant, anti-inflammatory, and antiapoptotic properties of the compound. In conclusion, puerarin might be a potential adjuvant agent for the prevention and treatment of DR. However, comprehensive studies are necessary to show its effectiveness and safety, particularly in human.
\end{abstract}

Implication for health policy/practice/research/medical education:

Puerarin is one of the most famous isoflavones, which currently is used as an adjuvant agent in the treatment of different pathological conditions. Reviewing available evidences on the pharmacological activities and its underlying mechanisms can be helpful in the future treatment of retinopathy among diabetic patients.

Please cite this paper as: Fathalipour M, Mahmoodzadeh A, Safa O, Mirkhani M. Puerarin as potential treatment in diabetic retinopathy. J Herbmed Pharmacol. 2020;9(2):105-111. doi: 10.34172/jhp.2020.14.

\section{Introduction}

Diabetes mellitus is a progressive metabolic disorder characterized by high levels of blood glucose. Based on the report of International Diabetes Federation (IDF), the number of patients with diabetes is estimated to be doubled from 415 million in 2015 to 642 million in 2040 (1). Despite the high prevalence and rising trend, the micro- and macrovascular complications of diabetes are the main cause of morbidity and mortality, reduction in life expectancy, and high healthcare expenditures, particularly in diabetic elderly patients (2).

Diabetic retinopathy (DR) is one of the most prevalent complications of diabetes and the leading cause of visual loss among working-aged adults around the world (3). In a study, 92.6 million (34.6\%) patients with diabetes suffered from DR, of which 28.4 million patients afflicted with serious vision impairment (4). Several factors, including type and duration of diabetes, glycemic control and insulin resistance status, and the presence of risk factors of DR such as hypertension, smoking, and dyslipidemia are involved in the severity of DR (5).

The most effective strategies to delay the onset and prevent the progression of DR are tight glycemic control and treatment of comorbidities of diabetes including high blood pressure and dyslipidemia (6). Laser photocoagulation and vitrectomy are now the only approved treatments of late stages of DR (7). Recently, development of various pharmacological agents has remarkably improved the management of vision loss and retinal dysfunction (8). Intravitreal pharmacotherapy with anti-angiogenic and anti-inflammatory agents is the most commonly used protocol for both prevention and treatment of established DR (9). Moreover, several lines of studies are investigating and developing different classes of chemical constituents to manage DR. Natural remedies as invaluable and available compounds also have gotten attention of the researchers.

Puerarin is a polyphenolic compound isolated from 
various plants and herbs and intensively investigated for several beneficial activities. It is widely used as adjuvant agent in the treatment of neurodegenerative diseases, diabetes and its complications, cardiovascular and cerebrovascular diseases, and cancer $(10,11)$. A number of studies have shown this compound could prevent, and improve retinopathy in diabetes. In the present review, the beneficial impacts of puerarin in the treatment of DR were screened and the underlying mechanisms behind these pharmacological activities completely discussed.

\section{Pathophysiology of DR}

Although the exact pathogenesis of DR is not thoroughly understood, chronic hyperglycemia is seemed to be the primarily cause of this disease (12). There are four known molecular mechanism describing how hyperglycemia results in DR. The polyol pathway flux increases under hyperglycemic condition. Aldose reductase reduces intracellular glucose to sorbitol, and aldehydes to inactive alcohols with depletion of nicotinamide adenine dinucleotide phosphate (NADPH) and reduced glutathione. Subsequently, sorbitol dehydrogenase oxidizes sorbitol to fructose with consumption of nicotinamide adenine dinucleotide $\left(\mathrm{NAD}^{+}\right)$(13). Moreover, intracellular production of advanced glycation end-products (AGEs) increases under hyperglycemic condition. Non-enzymatic modifications of intracellular and matrix proteins alter various cellular functions, and cause abnormal interactions between several matrix proteins and integrins. Changes of plasma proteins produce ligands which bind to receptors of AGE (RAGEs), and result in generation of intracellular reactive oxygen species (ROS), and changes in expression of several gens (14). Intracellular hyperglycemia also increases diacylglycerol content, and activates protein kinase C, which has numerous pathogenic effects, especially activation of nuclear factor kappa light chain enhancer of activated B cells (NFkB) and NADPH oxidases (15). Furthermore, hyperglycemia-induced activation of the hexosamine pathway leads to several alternations in both gene expression and protein function (16).

A body of evidence has demonstrated hyperglycemiainduced oxidative stress and inflammation along with apoptosis are the main reasons responsible for overexpression of retinal growth factors (particularly vascular endothelial growth factor, VEGF), retinal hemodynamic changes, and impairment in neurotrophic factor receptors and their signaling pathway, which damage to retinal vessels, neurons, and glial cells $(3,17,18)$. These pathogenic mechanisms involve in retinal microvasculopathy as well as early neuropathy, and lead to retinopathy and vision impairment.

\section{Puerarin}

Puerarin as one of the most famous isoflavone was isolated from Pueraria lobata in the 1950s for the first time. The polyphenolic structure of puerarin is demonstrated in Figure 1. Several line of studies have intensively investigated the pharmacological properties of this compound. There are some commercially dosage forms of puerarin for oral and injection applications, and currently used as an adjuvant therapy in the management of cancer (11), neurodegerative diseases (19) including Alzheimer's and Parkinson's diseases, vascular diseases (20), liver injuries (21), and osteoporosis (22). Injection form of puerarin has been approved by State Food and Drug Administration of China (SFDA) for the treatment of myocardial infarction as well as angina pectoris. Documented evidences have also demonstrated puerarin has a protective role against diabetes mellitus (23) and its complications, specially DR.

\section{Diabetic retinopathy and puerarin}

The protective effects of puerarin have been investigated against DR in several pre-clinical and clinical studies. These beneficial impacts attributed to the abilities of this constituent to inhibit retinal oxidative stress, inflammation, apoptosis, vasculopathy, and neuropathy in hyperglycemic milieu. The effects of puerarin on in vitro and animal models of DR are summarized in Tables 1 and 2 , respectively.

\section{Antioxidant effects}

Several studies have shown that puerarin is able to act as a strong antioxidant factor, which exerts its effect via several pathways. Puerarin protects cells from oxidative-induced damage via induction of activity of antioxidant enzymes of glutathione S-transferase (38), superoxide dismutase (SOD), and catalase (39). Furthermore, puerarin acts its protective effect via activation of nuclear factor erythroid 2-related factor 2 (Nrf2) signaling pathway, which is a potent regulator for cellular defense system against toxic agents. Moreover, it has been shown that puerarin prevents complications of diabetes via attenuation of mitochondria derived ROS, especially by inhibition of NADPH oxidase $(40,41)$. On the other hand, puerarin, a phytoestrogen, is assumed to exert its antioxidant activities through induction of antioxidant/electrophile response element (ARE/EpRE)-mediated gene expression by activation of Nrf2-related factor 2-Keap 1 signaling pathway (42).

It is commonly accepted that puerarin has protective effects against DR through antioxidant activity. Puerarin<smiles>O=c1c(-c2ccc(O)cc2)coc2c([C@H]3O[C@H](CO)[C@@H](O)[C@H](O)[C@H]3O)c(O)ccc12</smiles>

Figure 1. The polyphenolic structure of puerarin. 
potentiated SOD activity in retinal tissue of streptozotocin (STZ)-induced $(31,33)$ and N-methyl-D-aspartate (NMDA)-induced retinopathy (26). The activity and expression of SOD also increased in retinal ganglion cells (RGCs) treated with NMDA (26), and mouse retinal pigment epithelial cells (MRPEs) treated with peroxynitrite (29) following the intervention with puerarin. The levels of malondialdehyde (MDA) decreased in different in vitro $(24,26)$ and animal models $(26,31-33)$ of DR after intervention with puerarin. Puerarin also ameliorated the production of nitrotyrosine in various models of retinopathy $(29,32,36)$.

AGE is one of the sources of ROS under hyperglycemic condition, which plays a critical role in the pathogenesis of DR (43). AGE-mediated damages are exerted via interaction of AGEs to the RAGEs, which activates ROS producing enzyme of NAPDH oxidases, and consequently, increased intracellular ROS formation (44). Several studies have reported that the increased production of ROS in retinal tissue of animal models (26) as well as in vitro models $(24-26,28)$ of retinopathy attenuated in the presence of puerarin. Moreover, puerarin caused a decrease in the production of retinal AGE $(30,34)$ along with a reduction in the expression and protein level of RAGE $(33,34)$ in animal models of DR. Puerarin also diminished the NADPH oxidase activity of bovine retinal pericyte cells (BRPCs) in AGE-induced retinopathy model (28).

Puerarin decreased the expression of retinal inducible nitric oxide synthase (iNOS) in STZ-induced diabetic rats $(32,36)$, and inhibited over production of nitric oxide (NO) and peroxynitrite (26). The protective effects of puerarin is mediated via inhibition of over expression of iNOS and peroxynitrite generation mediated through cell surface death receptor/cell surface death receptor ligand (Fas/FasL) signal pathway $(32,36)$. Moreover, the

Table 1. The effects of puerarin on diabetic retinopathy in in vitro models

\begin{tabular}{|c|c|c|c|}
\hline Author, Year & Cell lines & Models & Observed effects \\
\hline Wang, 2017 (24) & ARPE-19 & $A \beta$-induced retinopathy & $\begin{array}{l}\text { - Decreased ROS and MDA level } \\
-\quad \text { Activated of Nrf2/HO-1 signaling pathway } \\
\text { - Inhibited of IRE1 and PERK activation } \\
\text { - Inhibited of ATF6 activation }\end{array}$ \\
\hline Wang, 2016 (25) & Y-79 & Glutamate-induced retinopathy & $\begin{array}{l}\text { - } \text { Decreased ROS level } \\
\text { - Inhibited of CaMKII, ASK-1 and JNK activation } \\
\text { - Inhibited of p38 MAPK activation } \\
\text { - }\end{array}$ \\
\hline Lv,2016 (26) & RGC & NMDA-induced retinopathy & $\begin{array}{l}\text { - Decreased ROS, MDA and NO level } \\
\text { - Increased SOD activity } \\
\text { - } \text { Decreased expression of iNOS and Bax } \\
\text { - Increased expression and protein level of Bcl-2 } \\
\text { - } \\
\text { - } \\
\text { Ineduced caspases-3 activity and cell apoptosis } \\
\text { InhK and p38 MAPK activation }\end{array}$ \\
\hline Zhu, 2014 (27) & TR-iBRB2 & IL-1 $\beta$-induced retinopathy & $\begin{array}{l}\text { - Decreased expressions of VCAM-1 and ICAM-1 } \\
\text { - Decreased expression of Bax } \\
\text { - } \text { Increased expression and protein level of Bcl-2 } \\
\text { - Decreased cytochrome c level in cytosol } \\
\text { - }\end{array}$ \\
\hline Kim, 2012 (28) & BRPC & AGE-induced retinopathy & $\begin{array}{l}\text { - Decreased ROS level and NADPH oxidase activity } \\
\text { - Decreased luciferase activity } \\
\text { - } \text { Decreased NF-KB level } \\
\text { - } \text { Reduced cell apoptosis }\end{array}$ \\
\hline Hao, 2011 (29) & MRPE & Peroxynitrite-induced retinopathy & $\begin{array}{l}\text { - Decreased nitrotyrosine level } \\
\text { - } \text { Decreased expression and protein level of iNOS } \\
\text { - } \text { Decreased cytochrome c level in cytosol } \\
\text { - Inhibited of Fas activation } \\
\text { - Increased expression of SOD and Bcl-2 } \\
\text { - }\end{array}$ \\
\hline
\end{tabular}

ARPE-19; human adult retinal pigment epithelial cell, Y-79; retinoblastoma cell, TR-iBRB2; rat retinal capillary endothelial cell, BRPC; bovine retinal pericyte cell, MRPE; mouse retinal pigment epithelial cell, A $\beta$; amyloid beta, NMDA, N-methyl-D-aspartate, IL-1 $\beta$; interleukin 1 beta, AGE; advanced glycation end product, ROS; reactive oxygen species, MDA; malondialdehyde, SOD; superoxide dismutase, Nrf2/HO-1; nuclear factor erythroid 2-related factor 2/heme oxygenase-1, IRE1; inositol-requiring enzyme 1, PERK; protein kinase RNA-like ER kinase, ATF6; activating transcription factor 6, CaMKII; $\mathrm{Ca}^{2+/}$ calmodulin-dependent protein kinase II, ASK-1, CaMKII-dependent apoptosis signal-regulating kinase 1, JNK; c-Jun N-terminal kinase, p38 MAPK; p38 mitogen-activated protein kinases, NO; nitric oxide, iNOS; inducible nitric oxide synthase, Bcl-2; B-cell lymphoma protein 2, Bax; Bcl-2associated X protein, VCAM-1; vascular cell adhesion protein 1, ICAM-1; intercellular adhesion molecule 1, NADPH; nicotinamide adenine dinucleotide phosphate, NF-kB; nuclear factor kappa light chain enhancer of activated B cells, Fas; cell surface death receptor. 
Table 2. The effects of puerarin on diabetic retinopathy in animal models

\begin{tabular}{|c|c|c|c|}
\hline Author, Year & Models & Dose, route and duration & Effects on retinopathy \\
\hline $\begin{array}{l}\text { Liu, } \\
2019(30)\end{array}$ & STZ-induced retinopathy, rat & 80 mg/kg i.p. 4 weeks & $\begin{array}{l}\text { Decreased AGE-modified protein level } \\
\text { Prevented pathological changes }\end{array}$ \\
\hline $\begin{array}{l}\text { Cai, } \\
2017(31)\end{array}$ & STZ-induced retinopathy, rat & $\begin{array}{l}250,500 \mathrm{mg} / \mathrm{kg} \\
\text { p.o. } 4 \text { weeks }\end{array}$ & $\begin{array}{l}\text { Decreased MDA level and increase SOD activity } \\
\text { Decreased expression and protein level of STAT3 } \\
\text { Restored b-wave amplitude in electroretinography }\end{array}$ \\
\hline $\begin{array}{l}\text { Lv, } \\
2016(26)\end{array}$ & NMDA-induced retinopathy, rat & $\begin{array}{l}50 \mu \mathrm{g} / \mathrm{eye} \\
\text { i.v. Single dose }\end{array}$ & $\begin{array}{l}\text { Decreased ROS and MDA level } \\
\text { Increased SOD activity } \\
\text { Prevented RGC loss }\end{array}$ \\
\hline $\begin{array}{l}\text { Kim, } \\
2012(28)\end{array}$ & AGE-induced retinopathy, rat & $\begin{array}{l}25 \mu \mathrm{g} / \mathrm{eye} \\
\text { i.v. Single dose }\end{array}$ & $\begin{array}{l}\text { Decreased 8-OHdG level } \\
\text { Reduced cell apoptosis } \\
\text { Prevented pericyte loss }\end{array}$ \\
\hline $\begin{array}{l}\text { Hao, } \\
2012 \text { (32) }\end{array}$ & STZ-induced retinopathy, rat & $\begin{array}{l}140 \mathrm{mg} / \mathrm{kg} \\
\text { i.p. } 20,40 \text { and } 60 \text { days }\end{array}$ & $\begin{array}{l}\text { Decreased MDA and nitrotyrosine levels } \\
\text { Decreased expression of iNOS } \\
\text { Inhibited of Fas activation } \\
\text { Reduced cell apoptosis }\end{array}$ \\
\hline $\begin{array}{l}\text { Chen, } \\
2012(33)\end{array}$ & STZ-induced retinopathy, rat & $\begin{array}{l}500 \mathrm{mg} / \mathrm{kg} \\
\text { p.o. } 4 \text { weeks }\end{array}$ & $\begin{array}{l}\text { Decreased MDA level and increase SOD activity } \\
\text { Decreased expression and protein level of VEGF } \\
\text { Decreased expression and protein level of RAGE }\end{array}$ \\
\hline $\begin{array}{l}\text { Chen, } \\
2011(34)\end{array}$ & STZ-induced retinopathy, rat & $\begin{array}{l}250,500 \mathrm{mg} / \mathrm{kg} \\
\text { p.o. } 4 \text { weeks }\end{array}$ & $\begin{array}{l}\text { Decreased AGE level } \\
\text { Decreased expression and protein level of VEGF } \\
\text { Decreased expression and protein level of RAGE } \\
\text { Maintain ONL thickness }\end{array}$ \\
\hline $\begin{array}{l}\text { Chen, } \\
2011(35)\end{array}$ & STZ-induced retinopathy, rat & $\begin{array}{l}250,500 \mathrm{mg} / \mathrm{kg} \\
\text { p.o. } 4 \text { weeks }\end{array}$ & $\begin{array}{l}\text { Decreased NF-kB level } \\
\text { Reduced cell apoptosis } \\
\text { No improvement in mitochondrial metamorphosis } \\
\text { Restored b-wave amplitude in electroretinography }\end{array}$ \\
\hline $\begin{array}{l}\text { Hao, } \\
2010 \text { (36) }\end{array}$ & STZ-induced retinopathy, rat & $\begin{array}{l}160 \mathrm{mg} / \mathrm{kg} \\
\text { i.p. } 2 \text { months }\end{array}$ & $\begin{array}{l}\text { Decreased nitrotyrosine and complement } 3 \text { levels } \\
\text { Decreased expression of iNOS } \\
\text { Reduced cell apoptosis } \\
\text { Inhibited of Fas activation }\end{array}$ \\
\hline $\begin{array}{l}\text { Teng, } \\
2009 \text { (37) }\end{array}$ & STZ-induced retinopathy, rat & $\begin{array}{l}80 \mathrm{mg} / \mathrm{kg} \text {, } \\
\text { i.p. } 1,3 \text { and } 5 \text { months }\end{array}$ & $\begin{array}{l}\text { Decreased expression of VEGF and HIF-1 } \alpha \\
\text { Maintained the number of bipolar cells in INL and ONL } \\
\text { Decreased vacuolization in IPL } \\
\text { Reduced mitochondrial degenerative changes in ONL }\end{array}$ \\
\hline
\end{tabular}

STZ; streptozotocin, NMDA; N-methyl-D-aspartate, AGE; advanced glycation end product, i.p.; intraperitoneal, p.o.; oral, i.v.; intravitreal; MDA; malondialdehyde, SOD; superoxide dismutase, ROS; reactive oxygen species, STAT3; Signal transducer and activator of transcription 3, RGC; retinal ganglion cell, RPE; retinal pigment epithelial cell, 8-OHdG; deoxyguanosine, iNOS; inducible nitric oxide synthase, Fas; cell surface death receptor, VEGF; vascular endothelial growth factor, RAGE; receptor of AGE, ONL; outer nuclear layer, INL; inner nuclear layer, IPL; inner plexiform layer, NF-kB; nuclear factor kappa light chain enhancer of activated B cells, HIF-1 $\alpha$; hypoxia-inducible factor 1-alpha.

possible effect of puerarin on oxidative stress markers exerted through downregulation of signal transducer and activator of transcription 3 (STAT3) (31).

\section{Anti-inflammatory effects}

As it was mentioned before, inflammatory changes have been known as important contributors in the pathogenesis of DR. So, attenuation of inflammation could be invaluable in preventing retinal alterations in diabetic condition. Puerarin is able to act as an effective immunomodulator, and affect a wide range of inflammatory mediators including interleukin 1 beta (IL-1 $\beta$ ), interleukin 6 (IL-6), tumor necrosis factor alpha (TNF- $\alpha$ ), and iNOS (45). It has been shown that antiinflammatory activity of puerarin is mediated through alteration of several inflammatory associated signaling pathways, including extracellular signal-regulated kinase 1and 2 (ERK), and c-Jun N-terminal kinase (JNK) (46), NF- $\kappa B$ signaling cascade (47), insulin receptor substrate-1 (48), phosphoinositide 3-kinases (PI3Ks) and antioxidant response element-luciferase and translocation of Nrf2 (49), in various inflammatory models.

The anti-inflammatory activity of puerarin against DR has been examined in several studies. This compound inhibited IL-1 $\beta$-mediated leukostasis in rat retinal capillary endothelial cells (TR-iBRB2) via a decrease in expressions of vascular cell adhesion protein 1 (VCAM1) and intercellular adhesion molecule 1 (ICAM-1). Therefore, it is able to inhibit adhesion of leukocytes to the studied cells, and prevent consequent inflammatory 
events. Puerarin also inhibited inflammatory response by attenuating the activity and decreasing the level of NF$\kappa \mathrm{B}$ in retinal tissue of STZ-induced diabetic rats (35) and AGE-induced retinopathy in BRPC (28).

In spite of the current reports, it seems that the antiinflammatory effect of puerarin, especially in DR, needs further study. Future works should be focused on further clarifying the possible underlying mechanisms of action and finding more effective potential targets for the therapy of DR.

\section{Antiapoptotic effects}

Several studies have demonstrated that puerarin inhibited apoptosis in different in vitro and animal models of DR. Puerarin attenuated apoptosis in retinal tissue of STZinduced diabetic rats $(32,35,36)$. Furthermore, intravitreal injection of puerarin to the animal model of AGE-induced retinopathy could significantly decrease retinal terminal deoxynucleotidyl transferase dUTP nick end labeling (TUNEL)-positive cells (28). On the other hand, puerarin diminished glutamate-induced damage and apoptosis in retinoblastoma cells (Y-79) (25), IL-1 $\beta$-induced apoptosis in TR-iBRB2 cells (27), AGE-induced apoptosis in BRPC (28), and peroxynitrite-induced apoptosis in MRPE (29). The Antiapoptotic properties were related to the ability of puerarin in inhibition of mitochondrial dysfunction and p38 mitogen-activated protein kinases (p38 MAPK) activation $(25,26)$, reduction of caspases- 3 activity $(26,27)$, inhibition of Fas/FasL cascade $(29,32,36)$, and increase in B-cell lymphoma protein 2 (Bcl-2) expression (29). It has also been demonstrated that decrease in expression of $\mathrm{Bcl}$ 2 -associated X protein (Bax) $(26,27)$ as well as attenuation of intracellular oxidative stress $(25,28,29)$ had a main role in the antiapoptotic activity of puerarin. Moreover, both activating transcription factor 6 (ATF6) and protein kinase RNA-like ER kinase (PERK), which are involved in cell apoptosis, ameliorated by puerarin (24).

\section{Vasculoprotective activities}

As mentioned, damage to retinal microvasculature in hyperglycemic condition has a crucial role in pathogenesis of DR. VEGF as a key factor has an underlying role in retinal neovascularization and proliferative DR. Puerarin attenuated the expression of retinal VEGF in STZ-induced diabetic rats $(33,34)$. In addition to the downregulation of VEGF, puerarin decreases the expression of retinal hypoxia inducible factor 1 (HIF-1 $\alpha$ ) and modulator of VEGF expression in hypoxic condition, in diabetic rats (37). Hyperglycemia-induced over expression and function of iNOS can possess endothelial dysfunction in retinal tissue, which has a main role in the pathophysiology of DR. Several studies have reported that puerarin decreased the expression of iNOS in in vitro $(26,29)$ and animal models $(32,36)$ of DR. It has been mentioned that puerarin potentially is able to prevent blood-retinal barrier breakage.

\section{Neuroprotective activities}

Recent studies have reported that retinal neurodegeneration as well as retinal vasculopathy are involved in the pathogenesis of DR, particularly in the early stages of diabetes (12). Puerarin prevented retinal bipolar cell death in animal model of STZ-induced retinopathy (37), and RGC loss in NMDA-induced retinopathy (26). This compound also improved the decreased thickness of outer nuclear layer (ONL) in STZ-induced diabetic rats (34). Puerarin diminished glutamate-induced neurotoxicity in Y-79 cells, and the neuroprotective effects might be attributed to the inactivation of mitochondrial-dependent signaling pathway in the presence of glutamate. Puerarin inhibited CaMKII-dependent apoptosis signal-regulating kinase 1 (ASK-1)/JNK/p38 MAPK signaling pathway (25). The neuroprotective properties of this compound also studied in electroretinography of STZ-induced diabetic rats. Puerarin restored b-wave amplitude and improved retinal function $(31,35)$.

\section{Human studies}

Three studies have examined the therapeutic effects of puerarin in patients with DR (50-52). Different parameters of retinal hemodynamic and hemorheology were assessed using color Doppler ultrasonography method in diabetic patients. The obtained results demonstrated that puerarin improved the peak systolic and end diastolic velocity of central retinal artery as well as central retinal vein reflux velocity $(51,52)$. Moreover, puerarin restored naked eye

Table 3. The effects of puerarin on diabetic retinopathy in humans

\begin{tabular}{|c|c|c|c|c|c|}
\hline \multirow{2}{*}{ Author Year } & \multirow{2}{*}{ Study population } & \multicolumn{2}{|c|}{ Number of subjects } & \multirow{2}{*}{$\begin{array}{l}\text { Dose, } \\
\text { duration }\end{array}$} & \multirow{2}{*}{ Effects on retinopathy } \\
\hline & & Controls & Cases & & \\
\hline Zhang, 2013 (51) & Patients with DR & 43 & 43 & $400 \mathrm{mg} / \mathrm{d}, 2$ months & $\begin{array}{l}\text { - Improved retinal hemodynamics } \\
\text { - Improved retinal hemorheology }\end{array}$ \\
\hline Wang, 2012 (50) & Patients with DR & 15 & 15 & $400 \mathrm{mg} / \mathrm{d}, 15$ days & $\begin{array}{l}\text { - Improved retinal hemodynamics } \\
\text { - Improved retinal hemorheology }\end{array}$ \\
\hline Ren, 2000 (52) & Patients with DR & - & 87 & $400 \mathrm{mg} / \mathrm{d}, 3$ weeks & $\begin{array}{l}\text { - Improved retinal hemodynamics } \\
\text { - Improved retinal hemorheology } \\
\text { - Improved naked eye visions }\end{array}$ \\
\hline
\end{tabular}

DR; diabetic retinopathy, CRA; central retinal artery, CDU; color Doppler ultrasonography. 
vision and attenuated clinical symptoms of DR. A brief summary of clinical studies evaluating the role of puerarin in DR is presented in Table 3.

It will be useful to evaluate the safety and tolerability of puerarin rather than its effectiveness. Hence, high-quality clinical trials with larger population size and longer period of intervention should be conducted to evaluate the impacts of this compound on DR.

\section{Conclusion}

Puerarin attenuates retinal neovascularization and neurodegeneration in diabetes. The beneficial effects are attributed to the antioxidant, anti-inflammatory, and antiapoptotic properties of the compound. Puerarin might be a potential adjuvant agent for the prevention and treatment of DR. however, adequate and high-quality clinical trials with larger population size and longer duration are necessary to show its effectiveness and safety.

\section{Acknowledgements}

The authors would especially like to thank the assistance of Dr. Maryam Saleh, PharmD for invaluable advice. This study was a part of the $\mathrm{PhD}$ thesis of Mohammad Fathalipour.

\section{Authors' contributions}

$\mathrm{HM}$ and MF conceived and designed research. MF, AM and OS conducted the searches and data extracting. MF and AM wrote the manuscript. All authors read and approved the manuscript.

\section{Conflict of interest}

The authors declare that thay have no conflict of interest.

\section{Funding/Support}

The authors received no financial support for the research, authorship, and publication of this article.

\section{References}

1. Ogurtsova K, da Rocha Fernandes JD, Huang Y, Linnenkamp U, Guariguata L, Cho NH, et al. IDF Diabetes Atlas: Global estimates for the prevalence of diabetes for 2015 and 2040. Diabetes Res Clin Pract. 2017;128:40-50. doi: 10.1016/j. diabres.2017.03.024.

2. Brownlee M. Biochemistry and molecular cell biology of diabetic complications. Nature. 2001;414(6865):813-20. doi: 10.1038/414813a.

3. Hammes HP. Diabetic retinopathy: hyperglycaemia, oxidative stress and beyond. Diabetologia. 2018;61(1):29-38. doi: 10.1007/s00125-017-4435-8.

4. Ting DS, Cheung GC, Wong TY. Diabetic retinopathy: global prevalence, major risk factors, screening practices and public health challenges: a review. Clin Exp Ophthalmol. 2016;44(4):260-77. doi: 10.1111/ceo.12696.

5. Olivares AM, Althoff K, Chen GF, Wu S, Morrisson MA, DeAngelis MM, et al. Animal models of diabetic retinopathy. Curr Diab Rep. 2017;17(10):93. doi: 10.1007/s11892-017-
0913-0.

6. Chistiakov DA. Diabetic retinopathy: pathogenic mechanisms and current treatments. Diabetes Metab Syndr. 2011;5(3):165-72. doi: 10.1016/j.dsx.2012.02.025.

7. Mohamed Q, Gillies MC, Wong TY. Management of diabetic retinopathy: a systematic review. Jama. 2007;298(8):902-16. doi: 10.1001/jama.298.8.902.

8. Duh EJ, Sun JK, Stitt AW. Diabetic retinopathy: current understanding, mechanisms, and treatment strategies. JCI Insight. 2017;2(14). doi: 10.1172/jci.insight.93751.

9. Jonas JB. Intravitreal triamcinolone acetonide for diabetic retinopathy. Dev Ophthalmol. 2007;39:96-110. doi: 10.1159/000098502.

10. Wei SY, Chen Y, Xu XY. Progress on the pharmacological research of puerarin: a review. Chin J Nat Med. 2014;12(6):407-14. doi: 10.1016/s1875-5364(14)60064-9.

11. Zhou YX, Zhang H, Peng C. Puerarin: a review of pharmacological effects. Phytother Res. 2014;28(7):961-75. doi: $10.1002 /$ ptr.5083.

12. Whitmire W, Al-Gayyar MM, Abdelsaid M, Yousufzai BK, El-Remessy AB. Alteration of growth factors and neuronal death in diabetic retinopathy: what we have learned so far. Mol Vis. 2011;17:300-8.

13. Lorenzi M. The polyol pathway as a mechanism for diabetic retinopathy: attractive, elusive, and resilient. Exp Diabetes Res. 2007;2007:61038. doi: 10.1155/2007/61038.

14. Chen M, Curtis TM, Stitt AW. Advanced glycation end products and diabetic retinopathy. Curr Med Chem. 2013;20(26):3234-40. doi: 10.2174/09298673113209990025.

15. Gálvez MI. Protein kinase $\mathrm{C}$ inhibitors in the treatment of diabetic retinopathy. Review. Curr Pharm Biotechnol. 2011;12(3):386-91. doi: 10.2174/138920111794480606.

16. Semba RD, Huang H, Lutty GA, Van Eyk JE, Hart GW. The role of O-GlcNAc signaling in the pathogenesis of diabetic retinopathy. Proteomics Clin Appl. 2014;8(3-4):218-31. doi: 10.1002/prca.201300076.

17. Rübsam A, Parikh S, Fort PE. Role of Inflammation in Diabetic Retinopathy. Int J Mol Sci. 2018;19(4). doi: 10.3390/ ijms19040942.

18. Simó R, Stitt AW, Gardner TW. Neurodegeneration in diabetic retinopathy: does it really matter? Diabetologia. 2018;61(9):1902-12. doi: 10.1007/s00125-018-4692-1.

19. Lin F, Xie B, Cai F, Wu G. Protective effect of Puerarin on beta-amyloid-induced neurotoxicity in rat hippocampal neurons. Arzneimittelforschung. 2012;62(4):187-93. doi: 10.1055/s-0031-1299763.

20. Tan C, Wang A, Liu C, Li Y, Shi Y, Zhou MS. Puerarin improves vascular insulin resistance and cardiovascular remodeling in salt-sensitive hypertension. Am J Chin Med. 2017;45(6):1169-84. doi: 10.1142/s0192415x17500641.

21. Zhao M, Du YQ, Yuan L, Wang NN. Protective effect of puerarin on acute alcoholic liver injury. Am J Chin Med. 2010;38(2):241-9. doi: 10.1142/s0192415x10007816.

22. Wong R, Rabie B. Effect of puerarin on bone formation. Osteoarthritis Cartilage. 2007;15(8):894-9. doi: 10.1016/j. joca.2007.02.009.

23. Wong KH, Li GQ, Li KM, Razmovski-Naumovski V, Chan K. Kudzu root: traditional uses and potential medicinal benefits in diabetes and cardiovascular diseases. J Ethnopharmacol. 2011;134(3):584-607. doi: 10.1016/j.jep.2011.02.001.

24. Wang K, Zhu X, Zhang K, Yao Y, Zhuang M, Tan C, et al. Puerarin inhibits amyloid beta-induced NLRP3 inflammasome activation in retinal pigment epithelial cells 
via suppressing ROS-dependent oxidative and endoplasmic reticulum stresses. Exp Cell Res. 2017;357(2):335-40. doi: 10.1016/j.yexcr.2017.05.030.

25. Wang K, Zhu X, Zhang K, Wu Z, Sun S, Zhou F, et al. Neuroprotective effect of puerarin on glutamate-induced cytotoxicity in differentiated Y-79 cells via inhibition of ROS generation and Ca2+ influx. Int J Mol Sci. 2016;17(7):e1109. doi: 10.3390/ijms17071109.

26. Lv B, Huo F, Dang X, Xu Z, Chen T, Zhang T, et al. Puerarin attenuates N-Methyl-D-aspartic acid-induced apoptosis and retinal ganglion cell damage through the JNK/p38 MAPK pathway. J Glaucoma. 2016;25(9):e792-801. doi: 10.1097/ ijg.0000000000000505.

27. Zhu X, Xie M, Wang K, Zhang K, Gao Y, Zhu L, et al. The effect of puerarin against IL-1beta-mediated leukostasis and apoptosis in retinal capillary endothelial cells (TR-iBRB2). Mol Vis. 2014;20:1815-23.

28. Kim J, Kim KM, Kim CS, Sohn E, Lee YM, Jo K, et al. Puerarin inhibits the retinal pericyte apoptosis induced by advanced glycation end products in vitro and in vivo by inhibiting NADPH oxidase-related oxidative stress. Free Radic Biol Med. 2012;53(2):357-65. doi: 10.1016/j. freeradbiomed.2012.04.030.

29. Hao LN, Zhang YQ, Shen YH, Wang ZY, Wang YH. Inducible nitric oxide synthase and Fas/FasL with $\mathrm{C} 3$ expression of mouse retinal pigment epithelial cells in response to stimulation by peroxynitrite and antagonism of puerarin. Chin Med J (Engl). 2011;124(16):2522-9.

30. Liu J, Zhang Y, Cheng J, Tang X, Fu S, Ma L, et al. Puerarin reduces the levels of AGE-modified proteins in serum and retinal tissues to improve the retinal damage in diabetic rats. Lat Am J Pharm. 2019;38(2):396-405.

31. Cai $Y$, Zhang $\mathrm{X}, \mathrm{Xu} \mathrm{X}, \mathrm{Yu} \mathrm{Y}$. Effects of puerarin on the retina and STAT3 expression in diabetic rats. Exp Ther Med. 2017;14(6):5480-4. doi: 10.3892/etm.2017.5203.

32. Hao LN, Wang M, Ma JL, Yang T. Puerarin decreases apoptosis of retinal pigment epithelial cells in diabetic rats by reducing peroxynitrite level and iNOS expression. Sheng Li Xue Bao. 2012;64(2):199-206.

33. Chen F, Zhang HQ, Zhu J, Liu KY, Cheng H, Li GL, et al. Puerarin enhances superoxide dismutase activity and inhibits RAGE and VEGF expression in retinas of STZ-induced early diabetic rats. Asian Pac J Trop Med. 2012;5(11):891-6. doi: 10.1016/s1995-7645(12)60166-7.

34. Chen F, Liu KY, Xu S, Lü WH, Chen H, Zhang HQ. Experiment effect of puerarin on retina in diabetic rats induced by streptozotocin and its mechanisms. Chin Pharmacol Bull. 2011;27(9):1279-84.

35. Chen F, Liu KY, Xu S, Li WH, Li GL, Zhang HQ. Protective effect of puerarin on retinopathy and its inhibitory effect on NF- $\kappa B$ activity in diabetic mellitus rats. Chin J Pharmaco Toxico. 2011;25(3):296-300.

36. Hao LN, Zhang YQ, Shen YH, Wang ZY, Wang YH, Zhang HF, et al. Effect of puerarin on retinal pigment epithelial cells apoptosis induced partly by peroxynitrite via Fas/FasL pathway. Int J Ophthalmol. 2010;3(4):283-7. doi: 10.3980/j. issn.2222-3959.2010.04.01.

37. Teng Y, Cui H, Yang M, Song H, Zhang Q, Su Y, et al. Protective effect of puerarin on diabetic retinopathy in rats. Mol Biol Rep. 2009;36(5):1129-33. doi: 10.1007/s11033-0089288-2.

38. Hwang YP, Choi CY, Chung YC, Jeon SS, Jeong HG. Protective effects of puerarin on carbon tetrachloride- induced hepatotoxicity. Arch Pharm Res. 2007;30(10):130917. doi: 10.1007/bf02980272.

39. Lian $\mathrm{D}$, Yuan $\mathrm{H}$, Yin $\mathrm{X}, \mathrm{Wu} \mathrm{Y,} \mathrm{He} \mathrm{R,} \mathrm{Huang} \mathrm{Y}$, et al. Puerarin inhibits hyperglycemia-induced inter-endothelial junction through suppressing endothelial Nlrp3 inflammasome activation via ROS-dependent oxidative pathway. Phytomedicine. 2019;55:310-9. doi: 10.1016/j. phymed.2018.10.013.

40. Li X, Cai W, Lee K, Liu B, Deng Y, Chen Y, et al. Puerarin attenuates diabetic kidney injury through the suppression of NOX4 expression in podocytes. Sci Rep. 2017;7(1):14603. doi: 10.1038/s41598-017-14906-8.

41. Li W, Zhao W, Wu Q, Lu Y, Shi J, Chen X. Puerarin improves diabetic aorta injury by inhibiting NADPH oxidase-derived oxidative stress in STZ-induced diabetic rats. J Diabetes Res. 2016;2016:8541520. doi: 10.1155/2016/8541520.

42. Rietjens I, Louisse J, Beekmann K. The potential health effects of dietary phytoestrogens. Br J Pharmacol. 2017;174(11):1263-80. doi: 10.1111/bph.13622.

43. Vlassara H, Uribarri J. Advanced glycation end products (AGE) and diabetes: cause, effect, or both? Curr Diab Rep. 2014;14(1):453. doi: 10.1007/s11892-013-0453-1.

44. Guimaraes EL, Empsen C, Geerts A, van Grunsven LA. Advanced glycation end products induce production of reactive oxygen species via the activation of NADPH oxidase in murine hepatic stellate cells. J Hepatol. 2010;52(3):389-97. doi: 10.1016/j.jhep.2009.12.007.

45. Ullah MZ, Khan AU, Afridi R, Rasheed H, Khalid S, Naveed $\mathrm{M}$, et al. Attenuation of inflammatory pain by puerarin in animal model of inflammation through inhibition of pro-inflammatory mediators. Int Immunopharmacol. 2018;61:306-16. doi: 10.1016/j.intimp.2018.05.034.

46. Wu H, Zhao G, Jiang K, Chen X, Zhu Z, Qiu C, et al. Puerarin exerts an antiinflammatory effect by inhibiting NF-kB and MAPK activation in Staphylococcus aureus-induced mastitis. Phytother Res. 2016;30(10):1658-64. doi: 10.1002/ ptr.5666.

47. Deng HF, Wang S, Li L, Zhou Q, Guo WB, Wang XL, et al. Puerarin prevents vascular endothelial injury through suppression of NF-kappaB activation in LPSchallenged human umbilical vein endothelial cells. Biomed Pharmacother. 2018;104:261-7. doi: 10.1016/j. biopha.2018.05.038.

48. Chen X, Yi L, Song S, Wang L, Liang Q, Wang Y, et al. Puerarin attenuates palmitate-induced mitochondrial dysfunction, impaired mitophagy and inflammation in L6 myotubes. Life Sci. 2018;206:84-92. doi: 10.1016/j.lfs.2018.05.041.

49. Fu C, Chen B, Jin X, Liu X, Wang F, Guo R, et al. Puerarin protects endothelial progenitor cells from damage of angiotensin II via activation of ERK1/2Nrf2 signaling pathway. Mol Med Rep. 2018;17(3):3877-83. doi: 10.3892/ mmr.2017.8317.

50. Wang B, Huo Y, Xu YL. Clinical effects of the puerarin on diabetic retinopathy by the ultrasound. Int Eye Sci. 2012;12(3):554-5

51. Zhang YQ, Zhang LM. Effects of puerarin treatment on hemodynamics and blood rheology in diabetic retinopathy patients. Int Eye Sci. 2013;13(10):2057-9. doi: 10.3980/j. issn.1672-5123.2013.10.34.

52. Ren $\mathrm{P}, \mathrm{Hu} \mathrm{H}$, Zhang R. [Observation on efficacy of puerarin in treating diabetic retinopathy]. Zhongguo Zhong Xi Yi Jie He Za Zhi. 2000;20(8):574-6. 